\title{
Basmati Rices: Genetics, Breeding and Trade
}

\author{
E. A. Siddiq $\cdot$ L. R. Vemireddy $\cdot$ J. Nagaraju
}

Received: 3 October 2011/ Accepted: 28 December 2011/Published online: 19 January 2012

(C) NAAS (National Academy of Agricultural Sciences) 2012

\begin{abstract}
Basmati rices, indigenous to the Indian sub-continent and endowed with unique quality traits are palatal delights of the rice connoisseurs world over. These virtues of Basmati rices command them premium price in domestic and international markets. Over the last several decades many studies have been carried out with the aim of understanding the extent of diversity of this speciality rice as well as genetics and breeding behavior of the key traits that distinguish Basmati from all other rices. In an attempt to obtain higher yield and to introduce resistance to pests and diseases without compromising on their quality, various breeding strategies which include recombination, mutation, hybrid and molecular breeding approaches have been pursued. In Basmati rice trade, patent and trademark claims by countries and organizations outside the natural habitat of Basmati rice, and issues relating to adulteration of Basmati rice with look-alike long grain non-Basmati grains by greedy traders have emerged as serious issues, which were required to be countered for protecting the burgeoning trade and the livelihood of poor farmers in the Himalayan foothills, the home of Basmati. Development and extensive commercial cultivation of high yielding Basmati varieties and hybrids, which fall short of the quality features of traditional Basmati varieties, since mid 90s have necessitated development of high throughput DNA marker assay for distinguishing the traditional Basmati varieties from the evolved or cross-bred Basmati varieties as well as from the lookalike non-Basmati varieties in order to ensure fair price for the farmers and to quantify admixtures in export consignments. In this review, we have made an attempt to highlight the efforts that have gone into study, improve and protect the Basmati.
\end{abstract}

Keywords Basmati rice - Genetics - Adulteration - Breeding - DNA markers

\section{Introduction}

Rice, the second most widely grown cereal crop, is the staple food for more than half of the world's population. Rice is endowed with amazing genetic diversity with more than one hundred thousand landraces and improved cultivars maintained in the germplasm collections spread worldover. Varietal diversification appeared to have

E. A. Siddiq · L. R. Vemireddy

Institute of Biotechnology, Acharya N.G.Ranga Agricultural

University, Rajendranagar, Hyderabad 500030, AP, India

E. A. Siddiq · J. Nagaraju $(\bowtie)$

Laboratory of Molecular Genetics, Centre for DNA

Fingerprinting and Diagnostics, Nampally, Hyderabad, India

e-mail: jnagaraju@cdfd.org.in occurred as a function of adaptation to diverse agro-climatic conditions coupled with conscious and continuous selection subsequently by man for his diverse quality preferences. A unique varietal group that has distinguished itself as a result of natural and human selection, which found wider acceptance all over the world as a speciality rice is called "Basmati rice".

The unique features of Basmati rices such as extra long slender grain, lengthwise excessive elongation on cooking, soft and fluffy texture of cooked rice, and pleasant aroma which together determine uniqueness of Basmati rice [4, 24, 37]. Aside their unique cooking quality, Basmati rices are also reported to have low glycemic index [12] and are micronutrient rich especially for iron and zinc [16]. Unlike other aromatic rices, the unique quality traits of Basmati rice found their expression only when they are grown in the 
north-western foot hills of the Himalayas in the Indian subcontinent. And, because of its geographic specific manifestation of quality features, Basmati is now a Geographical Indication (GI) belonging to a specific geographical area in the Indian subcontinent, and it is like "champagne" among wines and "scotch" among whiskies. Basmati has attained "heritage rice" status as it is considered as "farmers cultivar" being maintained and grown by farmers of Punjab region of India and Pakistan and Haryana and Uttar Pradesh regions of India for more than 250 years [25]. The special quality of Basmati rice is attributed to unique combination of soil, water, climate and cultural practices under which it is grown, besides the inherent genetics governing the features.

\section{History}

Earliest reference to the existence of aromatic rices in India can be traced to the documents of Susrutha (circa 400 BC), the great Indian pioneer in medicine and surgery. The first usage of the word "Basmati" is found in the Punjabi classic Heer Ranjah (1766) by the Punjabi poet Waris Shah [34]. The names of rice cultivars such as Basmati, Begumi and Satthi (60-day rice) suggest that "Basmati" rices might have been in the cultivation scene long before 1700 AD. Subsequent reference to "Basmati" can be found in "A Dictionary of the Economic Products of India" compiled by George Watt and published in 1891. The word "Basmati" appears to have been derived from two Sanskrit words i.e., vaas (fragrance) and matup (possessing). Vaasmati pronounced now as Basmati appears to mean the one that "possesses fragrance." In North India " $v a$ " is often pronounced as "ba", and that is how the word "vasmati" must have become "Basmati". Basmati rice was the preferred rice for preparation of Biryani and Pulao during festive season and special occasions. It was patronised by emperors, while poets have been composing poems admiring its qualities [25]. The credit for conserving and improving Basmati rices to suit various socioeconomic and agroclimatic conditions should go to farmers of the geographical region in the Indian subcontinent. The names of Basmati varieties that exist now are quite often suggestive of places, where they are predominantly grown. Haryana Basmati, for instance, is from Haryana and Dehradun Basmati (Type 3) from Dehradun area in Uttaranchal.

\section{Genetics}

Phylogenetic Relationships

Of 21 valid species that constitute genus Oryza, Oryza sativa (Asian cultivar) and Oryza glaberrima (African cultivar) are the only cultivated [36] species derived respectively from their perennial wild progenitors Oryza rufipogan and Oryza longistaminata (Fig. 1). Since its origin and domestication, the Asian cultivar has undergone differentiation into three distinct eco-geographical subspecies, viz., indica, japonica (temperate japonica) and javanica (tropical japonica) [31, 36]. The diversification of $O$. sativa does not confine to these three sub-species only as subsequent studies reveal further differentiation of the cultivar species into many more varietal groups largely as a result of human selection over centuries suiting diverse agroclimatic conditions, cultural practices and varied quality preferences. Isozyme analysis of Glaszmann [14] reveals Asian cultivar to have differentiated into six varietal groups viz., Indica, aus, ashina, rayada, aromatic and Japonica (Fig. 1). Earlier findings based on multivariate analysis using morpho-physiological traits by Vairavan et al. [35] also confirmed the cultivars to exist in as many as nine varietal groups. Significantly, both these studies categorize Basmati rices as a distinct group well separated from indica and japonica. Designated as Group $\mathrm{V}$ by Glaszmann, the aromatic rices are characterized by long slender grain and excessive elongation of kernels after cooking. As for their proximity to the typical indica and japonica subspecies is concerned, recent molecular characterization of Basmati group reveals that it is relatively closer to the japonica group contrary to the belief that it is closely related to the indica by virtue of its grain shape [13, 20]. Further Nagaraju et al. [24] in their study of genetic relationship of traditional Basmati (TB), evolved Basmati (EB) and non-Basmati (NB) varieties using simple sequence repeats (SSR) and fluorescent labelled inter-SSRPCR (FISSR) primers have shown that (a) traditional Basmati is distinctly different from non-Basmati rices and (b) as understood from their close relatedness Basmati varieties might be derivates of Punjab Basmati like or Dehraduni Basmati like common parent and whatever little genetic variation observed among them could be as a result of selection practiced over years by farmers. This view on the origin of TB varieties is consistent with the results obtained from the isozyme patterns of 60 of the 65 Pakistani Basmati accessions and nine Indian Basmati varieties which, with the exception of Karnal Local, matched with that of Basmati 370 and Dehraduni Basmati [30].

\section{Genetics of Key Quality Traits}

In the days of quality conscious consumers, no matter how expensive, demand for superior quality Basmati rice is on the increase in the domestic as well as international markets. For directed improvement of Basmati rices, knowledge of genetics of the key traits of Basmati quality is a prerequisite. Early efforts to understand the genetics and 
Fig. 1 Phylogenetic relationship of Basmati rice

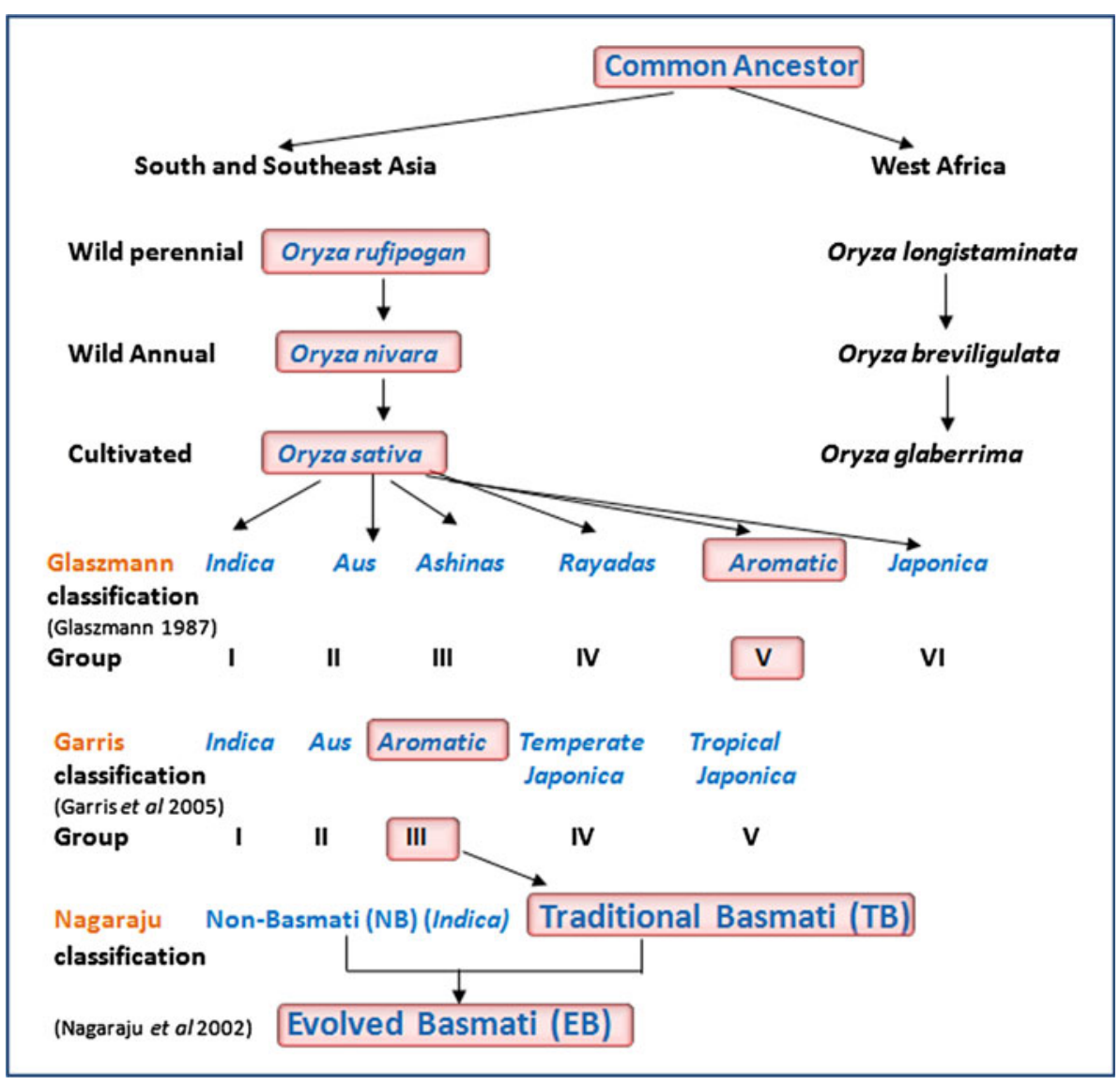

breeding behavior of the key indices of Basmati quality have revealed that all except aroma are polygenically controlled [33]. As for molecular mapping of genes/QTLs governing the key characteristics, only limited information is available. The following are the salient findings from genetic and mapping studies.

As of now, there are hardly any reports on molecular mapping of grain appearance traits, cooked kernel features and physico-chemical properties except aroma in Basmati rice. However, in Jasmine rice of Thailand, four QTLs for amylose content (AC), two for gel consistency (GC) and five for gelatinization temperature (GT) have been identified from a set of recombinant Inbred lines (RILs) derived from the cross of the jasmine variety KDML105 and non aromatic CT9933 that enabled to infer one major and a few modifier genes that govern AC, GC and GT [21]. Later, microsatellite markers RM225 and RM247 have been reported to be associated with grain breadth and cooked grain breadth, respectively based on bulked segregant analysis of $247 F_{2}$ individuals of the cross Basmati370/ ASD16 [15]. Subsequently, Amarawathi et al. [3] have identified three QTLs for grain length (L) on chromosomes 1 and 7, two each for grain breadth (B) and LB ratio on chromosome 7, three for aroma on chromosomes 3, 4 and 8 and one each for kernel elongation ratio on chromosome
11 , amylose content and alkali spreading value mapped to chromosome 6 in a mapping population involving Pusa1121, an evolved Basmati cultivar of extraordinary elongation ( $>2.5$ elongation ration) as one of the parents.

One of the key characteristics of Basmati for which it is commanding high premium price is its unique aroma. The Basmati aroma is found at all stages of crop growth in almost all aerial parts of plant except roots [10, 22, 33]. Development and retention of aroma is influenced by genetic and environmental factors. Aroma develops from a cocktail of more than 100 compounds which include hydrocarbons, alcohols, aldehydes and esters. Among many compounds the most prominent fragrance causing chemical compound in Basmati rices, Pandanus leaves, and jasmine rice has been found to be 2-acetyl-1-pyrroline (2-AP) [6, 8-10]. Study of genetics of aroma has been an attractive research topic and many researchers studied employing various sensory tests. But for a few like Reddy and Reddy [26] who reported two to three recessive or dominant genes to determine the fragrance, most believe Basmati fragrance is controlled by a single recessive gene $[17,33]$. Almost two decades of attempts to know the genetics of aroma at molecular level culminated in mapping of a single locus $(f g r)$ on chromosome 8. QTL mapping [1]; Lorieux et al. [22]), fine mapping [10], 
sequence analysis and complementation test [11] helped to conclude betain aldehyde dehydrogenase $(B A D H 2)$ to be the fragrance causing gene ( $f g r)$. Furthermore, badh2 allele in all the fragrant rice varieties is characterized by $8 \mathrm{bp}$ deletion and 3 SNPs in seventh exon [7] and 7 bp deletion in second exon [27] as compared to non-fragrant rice varieties suggesting that these events have occurred after the divergence of aromatic and non-aromatic varieties from the common ancestor (Fig. 2). Whereas the functional $B A D H 2$ converts $\mathrm{AB}$-ald (presumed 2-AP precursor) into GABA (4-amynobutyraldehyde) in non-fragrant rices and the non-functional $B A D H 2$ causes accumulation of $\mathrm{AB}$-ald and thereby enhances 2-AP biosynthesis in fragrant rices [11] (Fig. 2). A recent study by Kovacha et al. [20] suggests that Basmati cultivars were nearly identical to the ancestral japonica haplotype across $5.3 \mathrm{Mb}$ region flanking $B A D H 2$ indicating that Basmati cultivars had close evolutionary relationship with japonica varietal group.

Kernel elongation after cooking, an endosperm character unique to Basmati rices is basically a genetic trait but greatly influenced by factors like environment, ageing, etc. Despite being an important trait, not many reports are available on the inheritance of kernel elongation on cooking. Among the limited number of studies on this trait, one study has reported identification of a QTL on chromosome 8 and mapped it at a distance of $14.6 \mathrm{cM}$ employing two RFLP markers viz., RZ323 and RZ562 [2]. Recently, an extensive genome-wide mapping to dissect the genetic basis of all the quality traits of Basmati rice, have led the authors to identify and map several QTLs governing them (under publication).

\section{Breeding}

Conventional, Recombination and Molecular Breeding

Ever since the introduction of high yielding rice varieties, there have been scattered efforts to introduce Basmati quality traits into the background of high yielding varieties in India. Historically, systematic improvement of Basmati rice by pure line selection, to start with, was initiated in 1926 at Kalashah Kaku Rice Research Institute (KRRI) in the erstwhile Punjab province now in Pakistan. The first and most successful example of the pure line breeding strategy has been the development of Basmati 370 from a locally adapted landrace by Late Sardar Mohammad Khan in 1933 at KRRI. The pureline strategy continued remitting a few varieties resembling Basmati370, Dehradun Basmati etc. These varieties, although attained uniformity in grain quality, duration and stature, lacked resistance to yield affecting biotic stresses and genetic breed potential. Simultaneous attempts to cross breed among accessions of Basmati did not yield expected results because of lack of required genetic variability in the Basmati germplasm. The need to improve yield level of Basmati varieties prompted breeders since early 60 s to seek for crosses involving high yielding non-Basmati indica varieties. These attempts, by late 1980s, culminated in the development of as many as 25 high yielding semi-dwarf aromatic rice varieties with medium to long slender grains in India. Of these, 20 were not considered to be genetically closer to Basmati370 in quality and the remaining five too did not qualify for export as Basmati. Subsequent research efforts by pursuing
Fig. 2 Genetics and mapping of gene governing aroma

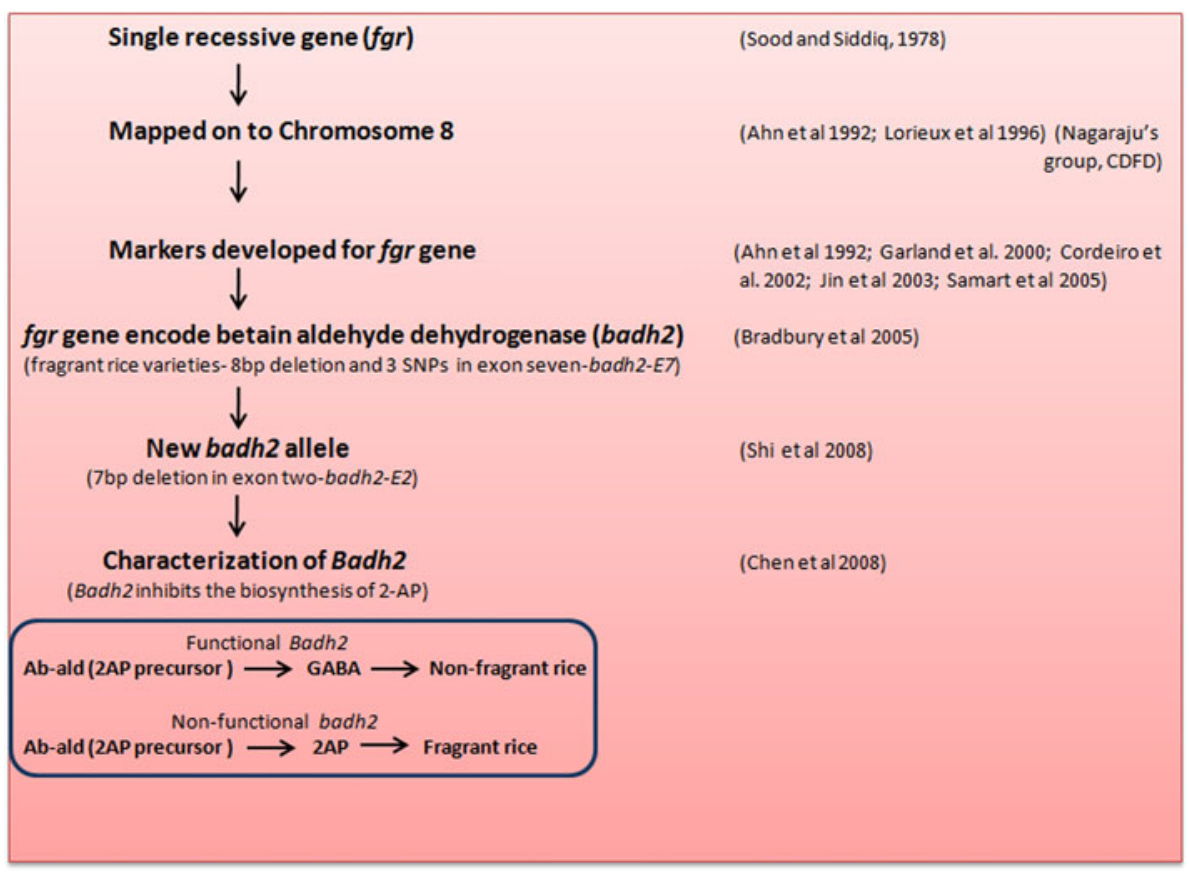


convergent breeding strategy for two and a half decades finally led to the development and release of the world's first high yielding semi-dwarf Basmati variety Pusa Basmati-1 in 1989 [29]. This variety registered 1.5-2.0 tonnes higher yield per hectare and compared very well in quality with the highly prized traditional Basmati varieties like Basmati370 and Taraori Basmati. Further, its extra elongation upon cooking ( $>2$ times), fine texture, taste and pleasant aroma provided an ideal replacement to traditional varieties for export. As a result, Pusa Basmati-1 accounted for $40-60 \%$ of the Basmati rice exported every year upto 2007-2008. Pusa Basmati-1 has earned in the last 15 years over Rs. 150 billion in foreign exchange for the country and brought prosperity to small farmers in the provinces of Punjab, Haryana, Western Uttar Pradesh and Uttarakhand that contribute the traditional Basmati growing area of the country. Also, following its extensive commercial planting, the country's export volume of Basmati quality rice increased several folds between 1990 and 2007-2008. In addition to remaining as a landmark variety, it served as donor variety for developing many progressively improved Basmati quality varieties and hybrids (Fig. 3). Although Pusa Basmati-1 is the most widely cultivated high yielding Basmati cultivar in India for more than 15 years, its susceptibility to bacterial leaf blight (BLB) warranted further breeding efforts to make it resistant to the disease. Advances in molecular marker technology have led to the selective incorporation of two BLB resistance genes viz., $x a 13$ and Xa21 from the non-Basmati isogenic donor source IRBB55 into Pusa Basmati-1. The resultant line was named as Pusa1460 [18] and notified as Improved Pusa Basmati 1 in the year 2007 (Tables 1, 2). As a result of resistance to BLB coupled with Pusa Basmati-1 grain traits the improved Pusa Basmati 1 variety gained popularity among farmers.

Later, many high yielding varieties with Basmati quality such as Sugandh series were evolved using Pusa Basmati-1 as one of the parents and released for general cultivation scene. Importantly, a sister line of Pusa Basmati-1 which possessed unique Basmati quality traits was improved further and released as Pusa1121 (Pusa Sugandh 4) in 2003 [29]. This variety shows quite rare Basmati quality traits which include extra long kernel $(8.33 \mathrm{~mm})$ and highest kernel elongation and elongation ratio upon cooking ever reported $(22 \mathrm{~mm}$ and $>2.5$, respectively), high volume expansion ( $>4$ times), strong aroma and appealing taste as compared to standard Basmati varieties [32]. Pusa Basmati 1121, a cross product of two sister lines i.e., P614-1-2 and P614-2-4-3 of Pusa Basmati-1, is unique in its exceptional grain elongation upon cooking. This trait has given high commercial value in both domestic and export markets.

However, the major drawback of this tall statured variety is its proneness to lodging, low yield and susceptibility to diseases. Recognizing these drawbacks, efforts to improve this variety led to the development of the non-lodging high yielding Pusa1401 in 2008. In addition, a series of early maturing high yielding Basmati quality and good cooking quality varieties, Pusa Sugandh 2 and Pusa Sugandh 3 in 2001 and Pusa Sugandh 5 released in 2005 were subsequently developed and released by IARI (Fig. 3). They are the products of the crosses of Pusa 3A, a Basmati quality CMS line with Haryana Basmati 1. These varieties, although not comparable to the traditional Basmati varieties and Pusa Basmati-1 in quality, enjoy popularity among farmers in areas where such varieties are in demand.

\section{Hybrid Breeding}

It was China which in its research pursuit to breach the yield level of the high yielding semi dwarf varieties, succeeded in developing and demonstrating hybrid technology with new yield threshold 30 years back. Impressed with the pace of development of the technology in China, India accelerated hybrid breeding research in 1989. Taking advantage of the improved male sterile lines developed at IRRI and the experience of China in hybrid rice breeding technology, India came out successfully with the five first generation hybrids by 1995 . One of the breeding objectives set out in the Hybrid Rice Technology network was to develop Basmati quality Hybrids. Unlike the development of non-Basmati hybrids, the task of tailoring Basmati quality was a challenging task as the development of parental lines was required to be incorporated with Basmati quality traits without much compromise. The task of developing CMSbased Basmati quality hybrid was primarily assigned to IARI. Pusa Basmati-1, identified as a perfect maintainer, was used a donor parent to develop wild abortive (WA) cytoplasmic sterility based CMS line, Pusa $3 \mathrm{~A}$ which has typical Basmati qualities. Subsequently a few more CMS lines such as Pusa 5A, Pusa 6A etc. were developed. In the absence of complete restorers in Basmati germplasm, development of restorer (R) lines was a serious setback which was overcome by an ingenious breeding strategy involving partially restoring Basmati varieties. Variedly fertile segregants in the populations of crosses involving the CMS line Pusa 3A and Haryana Basmati-1, the partial restorer led to the identification of many restorers which, by virtue of their yield potential and quality, were released as varieties. These varieties include Pusa Sugandh 2, 3 and 5. Of these restorers, Pusa Sugandh 2 crossed with the CMS line Pusa 6A led to the development of the world's first superfine grain aromatic rice hybrid "Pusa RH10" (Fig. 3). It was released by the Central Varietal Release Committee (CVRC) in 2001 for irrigated regions of Haryana, Delhi and Uttarakhand. Yielding 20-30\% higher than Pusa Basmati-1 with the least penalty on quality, the hybrid became very popular all over the Basmati growing 


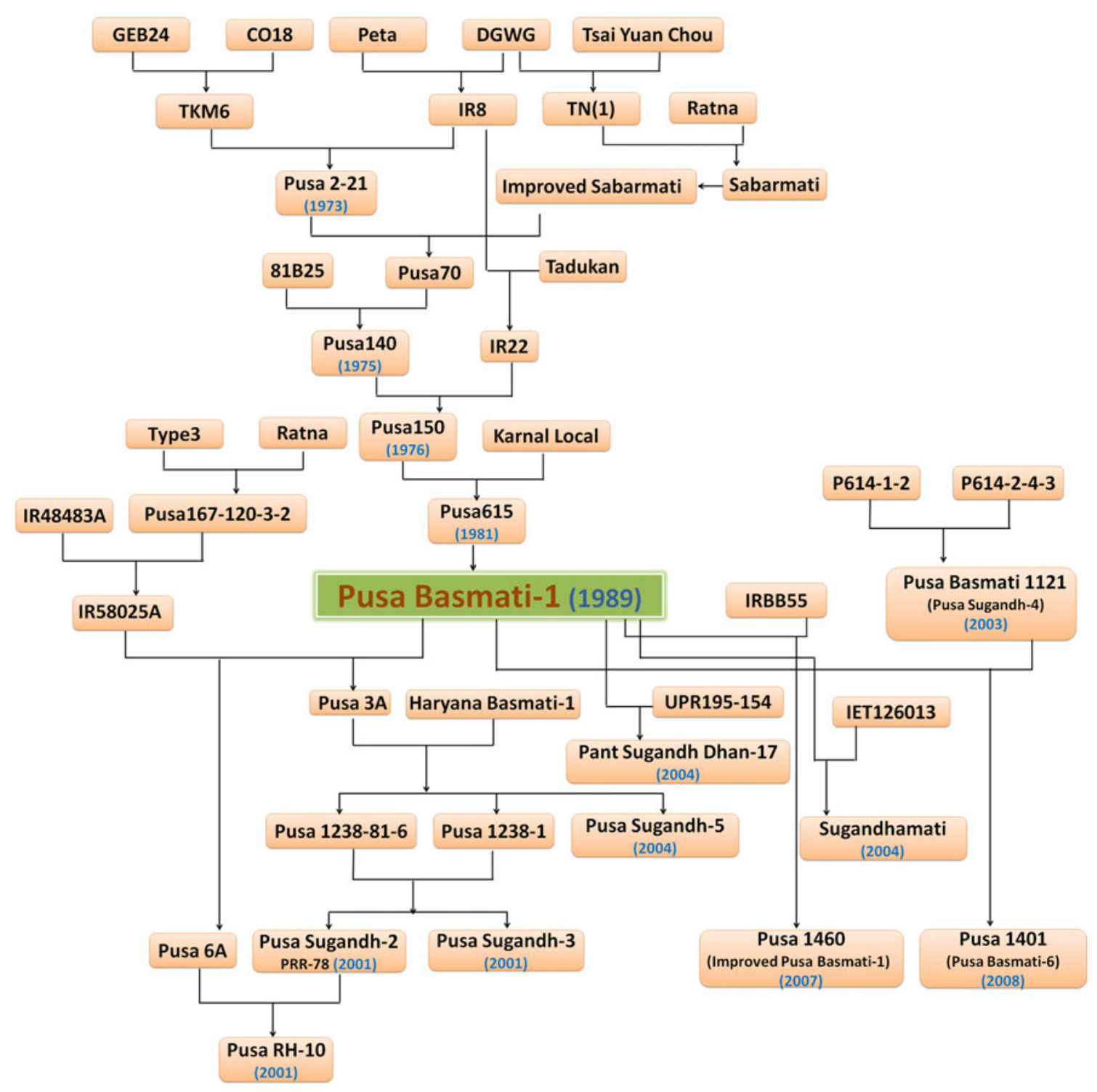

Fig. 3 Pedigree of Pusa Basmati-1 and its derived Basmati varieties

areas. Recently, the parents of Pusa RH10 have been incorporated with BLB resistance by employing marker assisted selection (MAS) [5]. The other Basmati type CMS lines, Pusa 6A, Pusa 7A, Pusa 8A, Pusa 9A, Pusa 10A and Pusa $11 \mathrm{~A}$, have also been developed and are being used in combination with several Basmati like restorer lines to produce Basmati hybrids. IRRI has also developed a few CMS lines and restorers from aromatic rices like IR67684 A, IR68280 A, IR68281 A, IR69617 A, and IR70372A. These lines have moderate to strong aroma and equal or more grain elongation ratio than Basmati370. The impact of breeding research spanning 40 years to evolve high yielding Basmati varieties and hybrids is clearly visible in the form of increase in production and export of Basmati rices earning sizeable foreign exchange for the country.
Trade

Export Quantum and Value

The introduction and extensive adoption of plant type based high yielding varieties since mid 60s have enabled the country not only achieve and sustain self sufficiency in food in general and rice in particular but also helped to reach sizeable surplus. The developments in rice scenario prompted the Government of India to come up with required policy measures to promote export of rice in general and highly prized Basmati rice in particular. Opening of Open general license (OGL) quota in 1980 provided an outlet for Basmati rice export triggering extensive cultivation of Basmati rices. 
Table 1 Notified Basmati varieties of India and Pakistan

\begin{tabular}{lllll}
\hline Cultivar & Pedigree & Method of development & Notified by & Type \\
\hline Basmati370 & Selection & Pure line selection & India, Pakistan & Traditional Basmati \\
Dehraduni Basmati & Selection from Type3 & Pure line selection & India & Traditional Basmati \\
Taraori Basmati & Selection from Basmati370 & Pure line selection & India & Traditional Basmati \\
Basmati386 & Selection from Pakistani Basmati & Pure line selection & India & Traditional Basmati \\
Ranbir Basmati & Selection from Basmati370 & Pure line selection & India & Traditional Basmati \\
Basmati217 & Punjab (Indian sub-continent) & Pure line selection & India & Traditional Basmati \\
Pusa Basmati-1 & Pusa150/Karnal Local & Convergent breeding & India & Evolved Basmati \\
Haryana Basmati & Sona/Basmati370 & Pedigree method & India & Evolved Basmati \\
Kasturi & Basmati370/CR 88-17-1-5 & Pedigree method & India & Evolved Basmati \\
Mahi sugandha & BK-79/Basmati370 & Pedigree method & India & Evolved Basmati \\
Punjab Basmati & TN1/Basmati370 & Pedigree method & India & Evolved Basmati \\
Pusa 1121 & Sister line of Pusa Basmati-1 & Convergent breeding & India & Evolved Basmati \\
Kernel Basmati & CM7/Basmati370 & Pedigree method & Pakistan & Evolved Basmati \\
Super Basmati & Basmati320/IR661 & Pedigree method & Pakistan, India & Evolved Basmati \\
Basmati385 & TN1/Basmati370 & Pedigree method & Pakistan & Evolved Basmati \\
Basmati198 & Basmati370/TN1 & Pedigree method & Pakistan & Evolved Basmati \\
\hline
\end{tabular}

Four types of rices being traded in the international markets are long grain indica (80\%), short grain japonica $(15 \%)$, aromatic rices that include Indian Basmati and Thailand Jasmine (4\%) and glutinous (1\%) rices. The limited market for aromatic rices is shared mainly by India and Pakistan and to some extent by Thailand. India has a major share in the Basmati export trade followed by Pakistan which is evident from the fact that speciality rice is exported today to over 90 countries across the world. Historically, even long before India became a surplus Basmati producer, it exported small quantity of this rice annually. The large scale exports started in early seventies with a TB variety, Dehradun Basmati and Uttar Pradesh became the first state to export Basmati rice to Arab countries. Since the development and extensive cultivation of the high yielding Pusa Basmati-1, area under production of Basmati rices has increased substantially. Annual export of Basmati rice in the country has touched 2 million tonnes, of which around two-thirds is exported. Percent share of Basmati rice to total rice exports is 58.14. Though Indian Basmati rice export has been experiencing low and high tides of trade in terms of volume and price due to competition from Pakistan and other aromatic rices like Jasmine of Thailand, still it is sustaining its place of importance. Asian countries (73.62\%) accounted for major share of import of Basmati rice from India followed by Western Europe (19.94\%). In terms of volume the share of Basmati rice to total rice exported is small. Yet, it generates three times higher returns (US\$ 600-1,200/tonne) over non-Basmati varieties (US\$200-400/tonne) in the overseas and domestic markets because of higher value. If we observe the trend of Basmati export, in 1991, 0.23 million tonnes earned Rs. 2.94 billion whereas it rose to Rs. 10.57 billion in 2010-2011 by exporting 2.18 million tonnes (http://agriexchange.apeda.gov.in).

Over one half of Basmati rice is exported as Sela (parboiled) to the Gulf countries particularly Saudi Arabia followed by Kuwait and UAE as well as UK and USA. With the opening of new markets like Japan, Korea, China, Iran and Indonesia under the WTO regime and also due to the removal of minimum export price by the Govt. of India, export volume of Indian rice in general and of Basmati rice in particular has increased many folds. Development and large scale cultivation of many high yielding varieties and hybrids of Basmati quality during the last 15 years in India and Pakistan have helped to consolidate and sustain growing export demand of Basmati rice. Keeping in view the export potential of Basmati rice, the Government of India have recently created two agri export zones (AEZ) one each in Punjab and Uttaranchal to further strengthen the export prospects.

\section{Patent and Trade-mark Issues}

On September 2nd 1997, the Texas-based American company Rice Tec Inc. was granted "varietal patent" (US5663484) for aromatic rices grown outside India and Pakistan as "Basmati" by the US Patent and Trademarks Office (USPTO). The company using "Basmati" as trademark for its brand names like "Texmati", "Kasmati" and "Jasmati" claimed their varieties as "novel" and "superior" to the traditional Basmati rices of India and Pakistan. The Rice Tec Patent included in all 20 claims related to (a) novel rice lines obtained from crosses of 
Table 2 Basmati quality rice varieties released in India till 2008

\begin{tabular}{|c|c|c|c|c|c|}
\hline IET no. & Variety & Parentage & Grain type & $\begin{array}{l}\text { Flowering } \\
\text { duration (days) }\end{array}$ & Year \\
\hline \multicolumn{6}{|c|}{ Central release } \\
\hline 10367 & Haryana Basmati 1 & Sona/Basmati 370 & $\mathrm{LS}$ & 110 & 1991 \\
\hline 18990 & $\begin{array}{l}\text { Improved Pusa } \\
\text { Basmati } 1\end{array}$ & PB 1/PB 1/IRBB 55 & $\mathrm{LS}$ & 105 & 2007 \\
\hline 8580 & Kasturi & Basmati 370/CR 88-17-1-5 & $\mathrm{LS}$ & 100 & 1989 \\
\hline 10364 & Pusa Basmati 1 & Pusa 150/Karnal Local & $\mathrm{LS}$ & 105 & 1989 \\
\hline 17251 & Pusa RH 10 & Pusa $6 \mathrm{~A} \times \mathrm{PRR} 78$ & $\mathrm{LS}$ & 95 & 2001 \\
\hline 16310 & Pusa Sugandh 2 & Pusa 1238-1/Pusa 1238-81-6 & $\mathrm{LS}$ & 105 & 2001 \\
\hline 16313 & Pusa Sugandh 3 & Pusa 1238-1/Pusa 1238-81-6 & LS & 105 & 2001 \\
\hline 17021 & Pusa Sugandh 5 & Pusa $3 \mathrm{~A} \times$ Haryana Basmati & LS & 102 & 2004 \\
\hline 16775 & Sugandhamati & Pusa Basmati $1 \times$ IET 12603 & $\mathrm{LS}$ & 114 & 2004 \\
\hline 15391 & Vasumathi & PR 109/Pak.Basmati & LS & 113 & 2001 \\
\hline 14720 & Yamini & BR4-10/Pak.Basmati & $\mathrm{LS}$ & 101 & 2001 \\
\hline 18990 & $\begin{array}{l}\text { Improved Pusa Basmati } \\
\text { (Pusa 1460) }\end{array}$ & Pusa Basmati-II/Pusa Basmati-1/IRBB55 & LS & 108 & 2007 \\
\hline 18005 & $\begin{array}{l}\text { Pusa Basmati } 6 \\
\text { (Pusa 1401) }\end{array}$ & Pusa Basmati-1/Pusa 1121-92-8-2-7-1 & LS & 119 & 2008 \\
\hline \multicolumn{6}{|c|}{ State release } \\
\hline \multicolumn{6}{|c|}{ Andhra pradesh } \\
\hline 15824 & Sumati & Chandan/Pak. Basmati & LS & 105 & 2001 \\
\hline \multicolumn{6}{|l|}{ Bihar } \\
\hline & Kamini & Pure line selection from Katarni rice & $\mathrm{LS}$ & 105 & 1991 \\
\hline \multicolumn{6}{|l|}{ Gujrat } \\
\hline & GR 101 & IR 8/Pankhari 203 & $\mathrm{LS}$ & 100 & 1984 \\
\hline \multicolumn{6}{|c|}{ Himachal Pradesh } \\
\hline 8580 & Kasturi & Basmati 370/CR 88-17-1-5 & $\mathrm{LS}$ & 100 & 1989 \\
\hline 15060 & Hasan Sarai & Introduction from Iran & $\mathrm{LS}$ & 95 & 2000 \\
\hline \multicolumn{6}{|l|}{ Haryana } \\
\hline & Taroari Basmati & Pure line selection from local Basmati & LS & 105 & 1996 \\
\hline \multicolumn{6}{|c|}{ Jammu \& Kashmir } \\
\hline 11348 & Ranbir Basmati & Selection from Basmati 370 & $\mathrm{LS}$ & 85 & 1995 \\
\hline \multicolumn{6}{|c|}{ Jharkhand } \\
\hline 18028 & Birsamati & IR 36/BR 9 & $\mathrm{LS}$ & 130 & 2003 \\
\hline \multicolumn{6}{|c|}{ Karnataka } \\
\hline 13549 & Mugad Sugandha & Selection from Basmati composite & LS & 100 & 2001 \\
\hline \multicolumn{6}{|c|}{ Madhya Pradesh } \\
\hline 3785 & Madhuri & 7aya/RII & LS & 84 & 1980 \\
\hline \multicolumn{6}{|c|}{ Maharashtra } \\
\hline & Ambica & MAU Sel-1 & LS & 88 & 1984 \\
\hline 12897 & Indrayani & Ambemohar 157/IR 8 & LS & 102 & 1987 \\
\hline 11338 & Pawana & IR8/Pusa 33 & $\mathrm{LS}$ & 90 & 1988 \\
\hline 10651 & Sakoli-7 & TN 1/Basmati 370 & LS & 100 & 1988 \\
\hline \multirow[t]{2}{*}{9296} & SYE-ER 1 & Sonal/SYE $44-3$ & LS & 185 & 1990 \\
\hline & SYE-2 & & LS & 105 & 1985 \\
\hline 13549 & Bhogavati & Selection from Basmati composite & LS & 100 & 2004 \\
\hline \multicolumn{6}{|c|}{ New Delhi } \\
\hline 18004 & $\begin{array}{l}\text { Pusa Sugandh } 4 \\
\text { Renamed as Pusa } \\
\text { Basmati } 1121\end{array}$ & $\mathrm{P}$ 614-1-2/P 614-2-4-3 & LS & 105 & 2003 \\
\hline
\end{tabular}


Table 2 continued

\begin{tabular}{|c|c|c|c|c|c|}
\hline IET no. & Variety & Parentage & Grain type & $\begin{array}{l}\text { Flowering } \\
\text { duration (days) }\end{array}$ & Year \\
\hline \multicolumn{6}{|l|}{ Orissa } \\
\hline & Geetanjali & Mutant of Basmati 370 & LS & 100 & 2005 \\
\hline \multicolumn{6}{|l|}{ Punjab } \\
\hline 13185 & Basmati 385 & $\begin{array}{l}\text { TN 1/Basmati } 370 \\
\text { (introduction from Pakistan) }\end{array}$ & LS & 105 & 1992 \\
\hline 14710 & Basmati 386 & Set from Pakistan Basmati & LS & 105 & 1994 \\
\hline 7313 & Punjab Basmati 1 & Sona/Basmati 370 & LS & 95 & 1982 \\
\hline \multirow[t]{2}{*}{18031} & Super Basmati & IR 662/Basmati 320 & LS & 110 & 2003 \\
\hline & Basmati $217^{a}$ & Selection from Local & $\mathrm{LS}$ & 115 & 1962 \\
\hline \multicolumn{6}{|c|}{ Rajasthan } \\
\hline \multirow[t]{2}{*}{7028} & BK 79 & TN1/NP 130//Basmati 370 & LS & 100 & 1981 \\
\hline & Khoshboo & Baran Basmati/Pusa 150 & LS & 100 & 1994 \\
\hline 12601 & Mahisugandha & BK 79/Basmati 370 & $\mathrm{LS}$ & 100 & 1994 \\
\hline \multicolumn{6}{|c|}{ Tamil Nadu } \\
\hline & Pusa $33^{\mathrm{a}}$ & Improved Sabarmati/Ratna & LS & 80 & 1975 \\
\hline 13544 & JJ 92 & Selection from Basmati 370 & LS & 80 & 1993 \\
\hline \multicolumn{6}{|c|}{ Uttar Pradesh } \\
\hline & Type 3 & Selection from Basmati Deharadun & LS & 115 & 1973 \\
\hline 19493 & MAUB 21 (Vallabh 21) & & LS & 130 & 2007 \\
\hline \multicolumn{6}{|c|}{ Uttarakhand } \\
\hline 14132 & Pant Sugandh Dhan 15 & Basmati 370/Sadri//Baharl/Muskan 41 & LS & 114 & 2002 \\
\hline 17263 & Pant Sugandh Dhan 17 & Pusa Basmati 1/UPRI 95-154 & LS & 105 & 2004 \\
\hline
\end{tabular}

Source Shobarani et al. [28]

a Denotified

traditional Basmati rice with long grain varieties (b) method of breeding the lines and (c) novel means of determining the cooking and starch properties. Basically, the claims attempted to establish that unlike the Indian Basmati rices that express the unique quality traits only when they are grown in the sub Himalayas region, the high yielding photo-sensitive lines developed by Rice Tec can be grown all over with qualities similar to Basmati and hence they are novel. Realizing the dangerous implications of allowing such a patent unchallenged, the government of India, through APEDA, legally challenged the US claims that they are neither novel nor generic. The inter-institutional technical committee involving the Directorate of Rice Research, Hyderabad and IARI, New Delhi of the ICAR (Indian Council of Agricultural Research) and Central Food Technology Research Institute (CFTRI) of CSIR (Council of Scientific and Industrial Research) prepared and submitted relevant documents to be used in re-examination proceedings. Finding that Rice Tec lines had no novelty whatsoever, the USPTO disallowed 15 of the 20 claims. In addition, they included amendment of the title of the patent from 'Basmati Lines and Grains' into
'Rice Lines Bas 367, RT 1117 and RT 1121'. The withdrawal of the claims 15-17 has averted the infringement of export of Basmati grains to USA from India. Also, the surrounding of the brand claims 1-5 also has stalled the alleged threat to export of grains of photo insensitive rice lines from India.

The Need and Initiatives for Protecting Basmati Rices as Geographical Indication (GI)

Geographical indication is a sign used for goods that originate from a specific geographical area and possess qualities or reputation that are due to characteristics unique to that particular area. Basmati rices are grown since centuries in the foot hills of the Himalayas covering the states of Punjab, Haryana, Uttar Pradesh and Uttaranchal in India and Punjab of Pakistan. They possess their special properties when grown under the agro-climatic conditions of the aforementioned region. Thus Basmati is a GI and not a generic type. Unfortunately this has not yet been protected under the GI of goods (Registration and Protection) Act, 1999. Had it been protected under this Act, Basmati name would have been protected from the unethical use by 
unauthorized persons, organizations such as Rice Tec to sell their lines using Basmati as the trademark for its Basmati like sounding 'Tasmati' 'Kesmati' etc. The enactment of Geographic indicators (GI) Act in 2003, has paved the way for registration of Basmati as a GI, for which APEDA (Agricultural Processed food products Export Developmental Authority) has taken initiative [23].

\section{Detection of Geographical Area}

As Basmati rice expresses its unique quality traits in its native area of cultivation, there is a need to determine the place of origin of the produce meant for export. Geographical area of cultivation can be determined by isotopic and multi element analyses of rice varietal samples [19]. In order to determine the Basmati geographical area, carbon $13 / 12$ and oxygen 18/16 ratios determined along with the concentration of elements like boron, holmium, gadolinium, magnesium, rubidium, selenium and tungsten. The levels of these elements and isotopes from the samples are compared with database values from authentic rice grown in India/Pakistan, USA and Europe. Combined isotopic and trace element analysis although can help distinguish the country of origin of the samples, the technique is however not able to distinguish mixtures of Basmati and long grain non-Basmati rices, which are commonly used as adulterants, from the same place of origin. In such situations, informative molecular markers, particularly microsatellite DNA markers and single nucleotide polymorphism (SNPs) can differentiate admixtures of Basmati and long grain rice.

\section{Quality and Food Safety for Sustainable Export}

\section{Scourge of Adulteration}

Despite their unique quality of high value the traditional Basmati varieties have many undesirable traits like lodging prone tall stature, low yield, photosensitivity etc. Attempts to increase yield level of Basmati varieties by cross breeding involving high yielding non-Basmati varieties resulted in proliferation of many 'evolved Basmati' varieties, which fall short of the quality standards defined for true Basmati varieties [4]. Thus these varieties have been given different "price grade" in the domestic as well as overseas export markets. The grading has become inevitable keeping in view the readiness of market to offer higher price to traditional Basmati than Basmati-like evolved varieties. In the European market, Indian traditional Basmati varieties (TB) like Dehraduni Basmati commands about $\$ 850$ as against about $\$ 500$ and $\$ 167$ per tonne offered to evolved Basmati varieties (EB) like Pusa Basmati-1 and PR106, respectively. Moreover, some rice importing countries like the European Union give zero percent import duty for six notified traditional Basmati varieties (European Commission regulation 1549/2004) hoping such a concession would benefit the small farmers who grow traditional Basmati rices in the Himalayan foot hills (Table 1). Taking this large price difference and zero percent import duty to their advantage unscrupulous traders export the premium TB varieties adulterated to different degrees with $\mathrm{EB}$ or NB varieties to earn more profits. Even by mixing traditional Basmati with $30 \%$ of evolved Basmati varieties traders can earn no less than \$100-120/MT profit while with non-Basmati varieties the fraudulent profit can be more than \$200/MT. Hence, the need arose to develop a precise method/protocol to distinguish TB from EB and NB varieties and to accurately quantify the adulterant(s).

\section{Detection and Quantification of Adulterant by DNA Marker Technology}

Considering that some inadvertent admixture of grains during harvest or post-harvest processing is not unusual, rice importing countries allow certain limit (5-15\%) of mixture. If any lot of Basmati rice exceeds the permitted limit of admixture, it is considered intentionally adulterated. Many Basmati importing countries particularly European nations have made it mandatory today for all consignments to have an authentication certificate based on DNA test for importing Basmati. Agricultural Processed Food Products Export Developmental Authority (APEDA) and the Centre for DNA Fingerprinting and Diagnostics (CDFD), Hyderabad, India, have established jointly "APEDA-CDFD Centre for Basmati DNA Analysis" to carryout DNA testing and certification of the export consignments. The CDFD developed a capillary electrophoresis (CE) based microsatellite DNA profiling protocol, which facilitates quick and accurate detection and quantification of adulteration in Basmati rice consignments. The single-tube assay multiplexes eight microsatellite loci viz., RM1, RM55, RM44, RM348, RM241, RM202, RM72 and RM171 to generate variety-specific allele profiles that can detect adulteration from $1 \%$ upwards with an accuracy of $\pm 1.5 \%[4,37]$. Based on the multiplex assay, more than 1,500 referral samples of Basmati rice destined to international market have so far been certified. The patents are pending for the protocol reported here (USPTO 10/357, 488 and 11/406, 257; PCT/ IN06/00254). The know-how on ready-to use kit has been transferred to $\mathrm{M} / \mathrm{S}$ Labindia (Indian partners of Applied Biosystems) under license transfer agreement.

\section{Conclusion}

Basmati rice of the Indian sub-continent, despite being the most expensive, is much in demand in the domestic and 
international markets. Taking advantage of the growing demand, premium price offered and the tariff concession available from the European Union, there is ample scope to expand the area under Basmati cultivation and thereby increase the export volume and forex earnings. Such strategy, however, warrants priority attention to certain research and development and policy related issues and associated problems. Given the kind of hassles the country had to pass through in challenging the patent protection obtained by an American Company on the ground that the name 'Basmati' is generic, the foremost issue to be addressed is legally protecting 'Basmati' rice as a GI. Evolved Basmati varieties meeting all the key quality traits can be designated as "Basmati". This being a policy issue, the Ministry of Commerce, in consultation with Indian Council of Agricultural Research (ICAR), should take appropriate decision in the interests of expanding export potentials. They would have, as we experience now, a place of their own as long as the consumer world looking for relatively less expensive Basmati rices exists. Further, to sustain the farmers profit of margin, production, and export, Government needs to enhance the minimum support price of Basmati rice. As for the expansion of area under the traditional Basmati rices, no matter how high commercial value they enjoy and forex earn because of certain trait(s) of aesthetic value, policy makers should exercise caution in promoting such a strategy, keeping in view the great challenging goal of making the country food and rice secure. While restricting the area under very low yielding traditional Basmati varieties to what is planted to now, we should rationally plan our future rice research and development strategies giving emphasis to evolve stress tolerant and nutritionally rich Basmati quality varieties and hybrids in high yielding backgrounds. Genomic tools especially molecular marker technology now available be used increasingly in breeding such value added varieties. Again, area under such cross-bred Basmati quality varieties be based on demand position in the domestic and international markets. The foresaid research priority should not mean that we neglect improvement of traditional Basmati rices. Absence apparently of needed variability for yield enhancement, defending against biotic stresses etc. could be overcome by strengthening diversity survey and screening for still uncovered traits of value using state of the art genomic tools available today.

\section{References}

1. Ahn SN, Bollich CN, Tanksley SD (1992) RFLP tagging of a gene for aroma in rice. Theor Appl Genet 84:825-828

2. Ahn SN, Bollich CN, McClung AM, Tanksley SD (1993) RFLP analysis of genomic regions associated with cooked-kernel elongation in rice. Theor Appl Genet 87:27-32
3. Amarawathi Y, Singh R, Singh A, Singh V, Mohapatra T, Sharma T, Singh N (2008) Mapping of quantitative trait loci for Basmati quality traits in rice (Oryza sativa L.). Mol Breed 21:49-65

4. Archak S, Lakshminarayanareddy V, Nagaraju J (2007) Highthroughput multiplex microsatellite marker assay for detection and quantification of adulteration in Basmati rice (Oryza sativa). Electrophoresis 28:2396-2405

5. Basavaraj SH, Singh VK, Singh A, Singh A, Singh A, Anand D, Yadav S, Ellur RK, Singh D, Krishnan SG, Nagarajan M, Mohapatra T, Prabhu KV, Singh AK (2009) Marker-assisted improvement of bacterial blight resistance in parental lines of Pusa RH10, a superfine grain aromatic rice hybrid. Mol Breed 26(2):293-305

6. Berner DK, Hoff BJ (1986) Inheritance of scent in American long grain rice. Crop Sci 26:876-878

7. Bradbury LMT, Fitzgerald TL, Henry RJ, Jin Q, Waters DLE (2005) The gene for fragrance in rice. Plant Biotech J 3:363-370

8. Buttery RG, Juliano BO, Ling LC (1982) Identification of rice aroma compound 2-acetyil-1-pyrroline in Panda leaves. Chem Ind (London) 23:478

9. Buttery RG, Ling LC, Juliano BO, Turnbaugh JG (1983) Cooked rice aroma and 2-acetyl-1-pyrroline. J Agric Food Chem 31:823-826

10. Chen S, Wu J, Yang Y, Shi W, Xu M (2006) The fgr gene responsible for rice fragrance was restricted within $69 \mathrm{~kb}$. Plant Sci 171:505-514

11. Chen S, Yang Y, Shi W, Ji Q, He F, Zhang Z, Cheng Z, Liu X, Xu M (2008) Badh2, encoding betaine aldehyde dehydrogenase, inhibits the biosynthesis of 2-acetyl-1-pyrroline, a major component in rice fragrance. Plant Cell 20:1850-1861

12. Foster-Powell K, Holt SHA, Brand-Miller JC (2002) International table of glycemic index and glycemic load values. Am J Clin Nutr 76:5-56

13. Garris AJ, Tai TH, Coburn J, Kresovich S, McCouch S (2005) Genetic structure and diversity in Oryza sativa L. Genetics 169:1631-1638

14. Glaszmann JC (1987) Isozymes and classification of Asian rice varieties. Theor Appl Genet 74:21-30

15. Govindaraj P, Arumugachamy S, Maheswaran M (2005) Bulked segregant analysis to detect main effect QTL associated with grain quality parameters in Basmati 370/ASD 16 cross in rice (Oryza sativa L.) using SSR markers. Euphytica 144:61-68

16. Gregorio GB (2002) Progress in breeding for trace minerals in staple crops symposium: plant breeding: a new tool for fighting micronutrient malnutrition. J Nutr 132:5005-5025

17. Jin QS, Waters D, Cordeiro GM, Henry RJ, Reinke RF (2003) A single nucleotide polymorphism (SNP) marker linked to the fragrance gene in rice (Oryza sativa L.). Plant Sci 165:359-364

18. Joseph M, Gopalakrishnan S, Sharma RK, Singh VP, Singh AK, Singh NK, Mohapatra T (2004) Combining bacterial blight resistance and Basmati quality characteristics by phenotypic and molecular marker-assisted selection in rice. Mol Breed 13(4):377-387

19. Kelly S, Baxter M, Chapman S, Rhodes C, Dennis J, Brereton P (2002) The application of isotopic and elemental analysis to determine the geographical origin of premium long grain rice. Eur Food Res Technol 214:72-78

20. Kovacha MJ, Calingacionb MN, Fitzgeraldb MA, McCouch SR (2009) The origin and evolution of fragrance in rice (Oryza sativa L.). Proc Natl Acad Sci USA 106(34):14444-14449

21. Lanceras JC, Huang ZL, Naivikul O, Vanavichit A, Ruanjaichon $\mathrm{V}$, Tragoonrung S (2000) Mapping of genes for cooking and eating qualities in Thai jasmine rice (KDML105). DNA Res 7:93-101

22. Lorieux M, Petrov M, Huang N, Guiderdoni E, Ghesqui ̈̈̈re A (1996) Aroma in rice: genetic analysis of a quantitative trait. Theor Appl Genet 93:1145-1151 
23. Money KS (2005) The path finder in promoting Indian Agri exports. Rice India 15:72-78

24. Nagaraju J, Kathirvel M, Kumar RR, Siddiq EA, Hasnain SE (2002) Genetic analysis of traditional and evolved Basmati and non-Basmati rice varieties by using fluorescence-based ISSRPCR and SSR markers. Proc Natl Acad Sci USA 99:5836-5841

25. Nene YL (1998) Basmati rice: a distinct variety (cultivar) of the Indian subcontinent. Asian Agri-History 2:321-330

26. Reddy VD, Reddy GM (1987) Genetic and biochemical basis of scent in rice (Oryza sativa L.). Theor Appl Genet 73:699-700

27. Shi W, Yang Y, Chen S, Xu M (2008) Discovery of a new fragrance allele and the development of functional markers for the breeding of fragrant rice varieties. Mol Breed 22(2):185-192

28. Shobarani N, Prasad GSV, Viraktamath BC (2009) National system for evaluation of Basmati rices for yield and quality traits Indian Farming, April, 7-12

29. Siddiq EA, Sigh VP, Zaman FU, Sadananda AR, Abraham MJ, Hariprasad AS, Mahendru A, Natrajan US, Nagarajan M, Atwal SS, Sinha SN, Chopra NK, Seth R, Mahapatra T, Prabhu KV, Sigh AK (2009) Development of high yielding Basmati quality rice varieties: a success story, Indian Farming, April, 13-17

30. Singh VP (2000) In: Singh RK, Singh US, Khush GS (eds) Aromatic rices. Oxford and India Book House, New Delhi, pp $135-153$

31. Singh RK, Singh US, Kush GS (2000) Aromatic rices. Oxford \&IBH Publishing Co. Pvt. Ltd., New Delhi

32. Singh VP, Singh AK, Atwal SS, Joseph M, Mohapatra T (2002) Pusa 1121: a rice line with e A.K. Exceptionally high cooked kernel elongation and Basmati quality. IRRN 27(1):25-26
33. Sood BC, Siddiq EA (1978) A rapid technique for scent determination in rice. Indian J Genet Plant Breed 38:268-271

34. Thakrar R, Ahuja SC (1993) Potential and prospects for export of basmati rice. In: Murlidharan K, Siddiq EA (eds) New frontiers in rice research. Directorate of Rice Research, Hyderabad, pp 382387

35. Vairavan S, Siddiq EA, Arunachalam V, Swaminathan MS (1973) A Study on the nature of genetic divergence in rice from Assam and North East Himalayas. Theor Appl Genet 43(5):213221

36. Vaughan DA, Morishima H, Kadowaki K (2003) Diversity in the Oryza genus. Curr Opin Plant Mol Biol 6:139-146

37. Vemireddy LR, Archak S, Nagaraju J (2007) Capillary electrophoresis is essential for microsatellite marker based detection and quantification of adulteration of Basmati rice (Oryza sativa). J Agric Food Chem 55:8112-8117

\section{Links related to Basmati rice}

www.Basmati.com

www.cdfd.org.in

www.food.gov.uk

www.apeda.com

www.tilda.com

www.the-south-asian.com

http://www.american.edu/ted/Basmati.htm

http://www.mcxindia.com/products_BasmatiRice.html 